Review

\title{
New Trends and Patterns in Sustainable Consumption: A Systematic Review and Research Agenda
}

\author{
Giulia Sesini ${ }^{\circ}$, Cinzia Castiglioni $*$ (1) and Edoardo Lozza \\ Department of Psychology, Università Cattolica, L.go Gemelli 1, 20123 Milano, Italy; \\ giulia.sesini1@unicatt.it (G.S.); edoardo.lozza@unicatt.it (E.L.) \\ * Correspondence: cinzia.castiglioni@unicatt.it
}

Received: 8 June 2020; Accepted: 21 July 2020; Published: 23 July 2020

check for updates

\begin{abstract}
The challenge of sustainable development and consumption is to meet current wants without impoverishing future generations and the planet in the long term. Therefore, new patterns of sustainable practices are increasingly promoted. The purpose of the present study is to realize a systematic review aimed to analyze the contents and features of articles dealing with new trends in consumers' sustainable consumption. One hundred and four papers published in the last five years were retrieved and analyzed through a lexicographical analysis using the software T-LAB. The results show that, even if most of the current studies focus almost exclusively on the environmental impact of sustainability, the social perspective is also recently taking hold. Evidence suggests prevailing attention towards consumers' appeal and consumption of eco-friendly food products, together with a growing interest in the last years in consumers' practices in other key sectors, such as tourism, commerce, and clothing. Future research should spotlight the less explored frameworks, looking at the economic and social sides of sustainability in a variety of contextual settings. At the same time, consumer-focused research should not forget to look at consumers' sustainable behavior as a whole and its impacts from the perspective of planet, people, and profit.
\end{abstract}

Keywords: sustainability; consumer behavior; review; new trends; computer-assisted content analysis

\section{Introduction}

Promoting sustainable consumption is a crucial aspect of sustainable development, which depends on achieving long-term economic growth that could ensure environmental and social needs for both present and future generations.

To understand what sustainable consumption is, it is advisable to first consider a paragraph from a guest editorial written by Peattie and Collins [1] (p. 108):

"More than one contributing author, when requested by referees to provide a clear and explicit definition of sustainable consumption, decline to on the basis that they do not believe attempts to settle on a single view were genuinely helpful."

This quote clearly embodies the idea that sustainable consumption represents a many-sided concept, entailing a large set of factors that can be analyzed from a variety of points of view. Indeed, a plethora of concepts have been investigated with regard to sustainable consumption, including responsible consumption, anti-consumption, consumer citizenship, and consumer lifestyles, to name only a few $[1,2]$.

To further understand what sustainable consumption means, it could be helpful to refer to the 'Brundtland definition' of sustainable development, which provides two clear criteria: meeting human needs and respecting the constraints aimed to preserve the capacity of the environment to respond to 
such needs [3]. In other words, sustainable development and consumption should meet current wants without impoverishing future generations and the planet in the long term [2]. The same concepts are also valid if applied to sustainable consumption. Indeed, the Oslo Symposium in 1994 provided a definition of sustainable consumption that recalls the principles expressed in the Brundtland Report, referring to the use of products and services responding to basic wants and minimizing resource depletion, in order to preserve the needs of future generations.

Considering evidence from different research fields suggesting that the demand of natural resources for human activities is beyond what is sustainable for the planet [1], the attention given to sustainability in recent decades by both research and institutions is unsurprising. As current consumption patterns are no longer sustainable, new patterns of sustainable practices are increasingly promoted [2]. In September 2015, the United Nations Member States adopted and approved the 2030 Agenda for Sustainable Development, a plan of action composed of 17 Sustainable Development Goals [4]. Encouraged actions involve three specific critical areas: people, planet, and prosperity. Indeed, if it is true that a huge number of studies focus almost exclusively on environmental aspects [1,5], the concept of sustainability is certainly broader. The Triple Bottom Line is a sustainability framework developed by Elkington [6], which focuses on the importance of considering all of the costs of doing business-that is, the ecological, social, and economic impacts. The environmental dimension concerns the impact of firm activities on natural resources; the social dimension involves the effect on society and population, enhancing living conditions and ensuring equal opportunities; and the economic dimension addresses the capacity to create value and income, improving the quality of life and well-being $[7,8]$.

In this context, sustainable consumer behavior is a key concept that can be analyzed from a variety of perspectives and methodologies. Stern [9] considers environmentally significant behavior to include those consumer practices that are characterized by the intention to change the environment-that is, by how decisions are driven to benefit or hinder their impact on the environment. Consumption needs to be looked at as a process of decisions and actions, not limited to the moment of purchase, but considering the whole lifecycle of a product or service [1,2]. Trudel [10] offers a comprehensive overview of the history of research investigating environmental and sustainable behavior. In the last decades of XX century, researchers focused on exploring the features of the 'green consumer' for segmentation purposes, although mainly leading to inconclusive results and privileging topics like energy preservation and recycling. Since 2000, the research agenda has embraced a decision-making perspective, introducing themes such as cognitive barriers, self-perceptions, social influence, and impact of product features [10].

The purpose of the present study is to realize a systematic review aimed to analyze the contents and features of articles dealing with new trends (i.e., development or changes in consumers' behavior) in consumers' sustainable consumption in the last five years through a lexicographical analysis. By consumption, we refer to the process of decisions and actions involving purchase, use, and disposal of goods, enacted by consumers [1]. Specifically, the search aims to investigate consumers' novel practices, which have attracted researchers' attention in the field of sustainability after the approval of the 2030 Agenda for Sustainable Development. The final objective is to detect trends among the selected articles, differentiating investigated variables and methodological features and disclosing insights on current tendencies in research. Consumers represent the center of our search, rather than production processes or sustainable development of industries.

Looking at past systematic reviews, it is clear that the range of investigated topics linked to consumers' sustainable consumption behavior is fairly heterogeneous. Among them, we can find several studies related to sharing economy [11,12], sustainable tourism [13], circular economy [14], attractiveness of sustainable features of products [15], food and beverage consumption [16], and impact of labels on purchase decisions [17-19]. All the above-mentioned reviews analyzed sustainable behavior, focusing on a specific domain. However, there are also a few instances of reviews that generally treated trends of sustainable practices. For instance, Kumar and Polonsky [20] addressed the 
topic of the 'green consumer' in general terms, looking at articles from 1975 to 2012 . We can also find a systematic review concerning new trends of sustainable consumption in Shao [21].

In this research, we aim to collect data about consumers' trends of sustainable behavior and practices with no specific distinction of sectors and practices, in order to recognize what features and tendencies characterize research on sustainable behavior as a whole. Through a lexicographical analysis, it is possible to support the review throughout the recognition and categorization of concepts and topics. To our knowledge, this is the first review concerning consumers' sustainable behavior to employ a lexicographical analysis methodology.

\section{Methodology}

The review protocol is based on the PRISMA (Preferred Reporting Items for Systematic Reviews and Meta-Analyses) statement for systematic reviews and meta-analysis, a checklist composed of 27 items guiding data selection and collection [22].

\subsection{Eligibility Criteria}

The following inclusion and exclusion criteria have been applied to select the studies: Inclusion criteria

- Peer-reviewed papers;

- Studies published after 2015, following the global mobilization of the 17 Sustainable Development Goals approved in September 2015 by the United Nations Members States throughout the 2030 Agenda for Sustainable Development [4];

- Full-text English written papers;

- Empirical papers;

- Research dealing with trends of sustainable consumption, focusing on consumers and their practices;

- Studies covering trends related to sustainable purchasing behavior as well as to services (like tourism and mobility).

\section{Exclusion criteria}

- Literature reviews, systematic reviews, conference papers (since not peer-reviewed publications), speculative and position papers, and meta-analysis;

- Studies covering interventions aimed to endorse sustainable behaviors, since our focus is on consumers' practices, not on how to endorse them;

- Articles dealing with new processes or methodologies to improve sustainable development of industries, production processes, and urban landscape development, since our aim is to concentrate on consumers' perspective.

\subsection{Information Source and Source Terms}

We chose to use the electronic database Scopus, which covers a wide range of areas and academic fields. The database was searched between 10 and 20 March. As noted above, the search included only studies published after 2015. Indeed, in September 2015 the United Nations Member States adopted and approved the 2030 Agenda for Sustainable Development, a plan of action composed of 17 Sustainable Development Goals [4].

The search terms were constructed so as to respond to the above-mentioned criteria. It was mandatory for all studies to describe some trends or practices related to sustainability, with a main focus on consumers. The following research was conducted:

- Scopus: TITLE-ABS-KEY (("trend" OR “pattern*" OR “habit" OR "profile*” OR "practice*”) AND ("consumer behavio* $r$ " OR "consumer attitude*") AND ("sustainability" OR "sustainable consumption")). 


\subsection{Study Selection}

The early selection stage involved screening titles and abstracts by all the authors in order to reach an agreed-upon initial pool. The remaining articles were searched to download the full-text version. After all papers were scanned, a definitive selection was made, and the resulting corpus was categorized for the information levels described in Section 2.4.

During all screening stages, the three authors first independently analyzed the articles and then confronted. Any doubt or disagreement was conjointly discussed by the authors to reach a common choice.

\subsection{Data Collection Process}

All the authors participated in the data collection. The data extraction was organized in a spreadsheet, and the following information was retrieved:

1. Who is(are) the author(s)?

2. What journal published the paper?

3. Which academic field does the journal belong to?

4. When was the study published?

5. How many times was the article cited?

6. Was the study conducted in a cross-cultural context? In which country(ies)?

7. Which methods were used in the research?

8. Which dimension of sustainability does the article investigate?

9. Which sustainability aspect does the study focus on?

10. Which industry sector does the research involve?

The last three information levels deserve a separate mention. In the current analysis, the Triple Bottom Line was used to distinguish among the three pillars of sustainability-that is, environmental, social, and economic dimensions [6]. An additional categorization level aimed to discriminate the type of sustainable practice, habit, or aspect that was mainly explored (e.g., attractiveness towards eco-friendly food, sustainable practices such as recycling and wasting, consumption of goods produced in sustainable way). Last, we also encoded the industry sector where the research was handled (e.g., food and beverage, housing, services). In Section 3, specific information about all the categorization levels is provided.

\subsection{Software and Analytical Strategy}

A lexicographical analysis was conducted using the software T-LAB, version 9.1 (T-LAB di Lancia Franco, Roccasecca, Italy), which supports linguistic, statistical, and graphical text analysis [23]. The analysis is based on the occurrences and co-occurrences of lexical units (LU) within a textual corpus or context units (CU). In the T-LAB database each lexical unit is a classified record with two fields: words-as they appear in the textual corpus, and lemmas-the dictionary form of a set of words (i.e., 'run' is the lemma of 'running' and 'runs'), whose labels in T-LAB are listed according to linguistic criteria or by dictionaries and semantic grids defined by the authors. T-LAB allows for exploring and mapping the significant linguistic elements without a priori interpretative hypothesis. This software explores the co-occurrence of relationships between key terms within a subset of text. After a prior conceptualization activity to encode the articles through the variables listed in Section 2.1, two different analyses were performed on the titles and abstracts of selected papers.

First, a specificity analysis was run to identify specific lemmas and words characterizing the corpus. We were interested in verifying whether some key elements were typical of the three dimensions of sustainability (environmental, social, and economic) and whether some others were commonly absent. The output consisted of a table reporting all significant lexical units together with their occurrence and chi-square value. Then, a correspondence analysis was conducted to map the relationships between words and categorical variables [24]. This technique made it possible to organize data in thematic clusters, which are represented in a two-dimensional chart. 


\section{Results}

The complete description of the flow process is presented in Figure 1. At the early stage, 207 articles resulted from Scopus, and no duplicated article was found. The identified papers were screened in several steps employing the above-mentioned exclusion and inclusion criteria. First, after analyzing titles and abstracts, 93 studies that did not meet the inclusion criteria were excluded. The remaining 114 studies were scanned in full-text papers. After downloading and scanning the full text of these 114 articles, a final pool of 104 papers meeting all the aforementioned criteria remained (see Box A1, Appendix A). In the last step, all the authors deeply analyzed and categorized these papers.

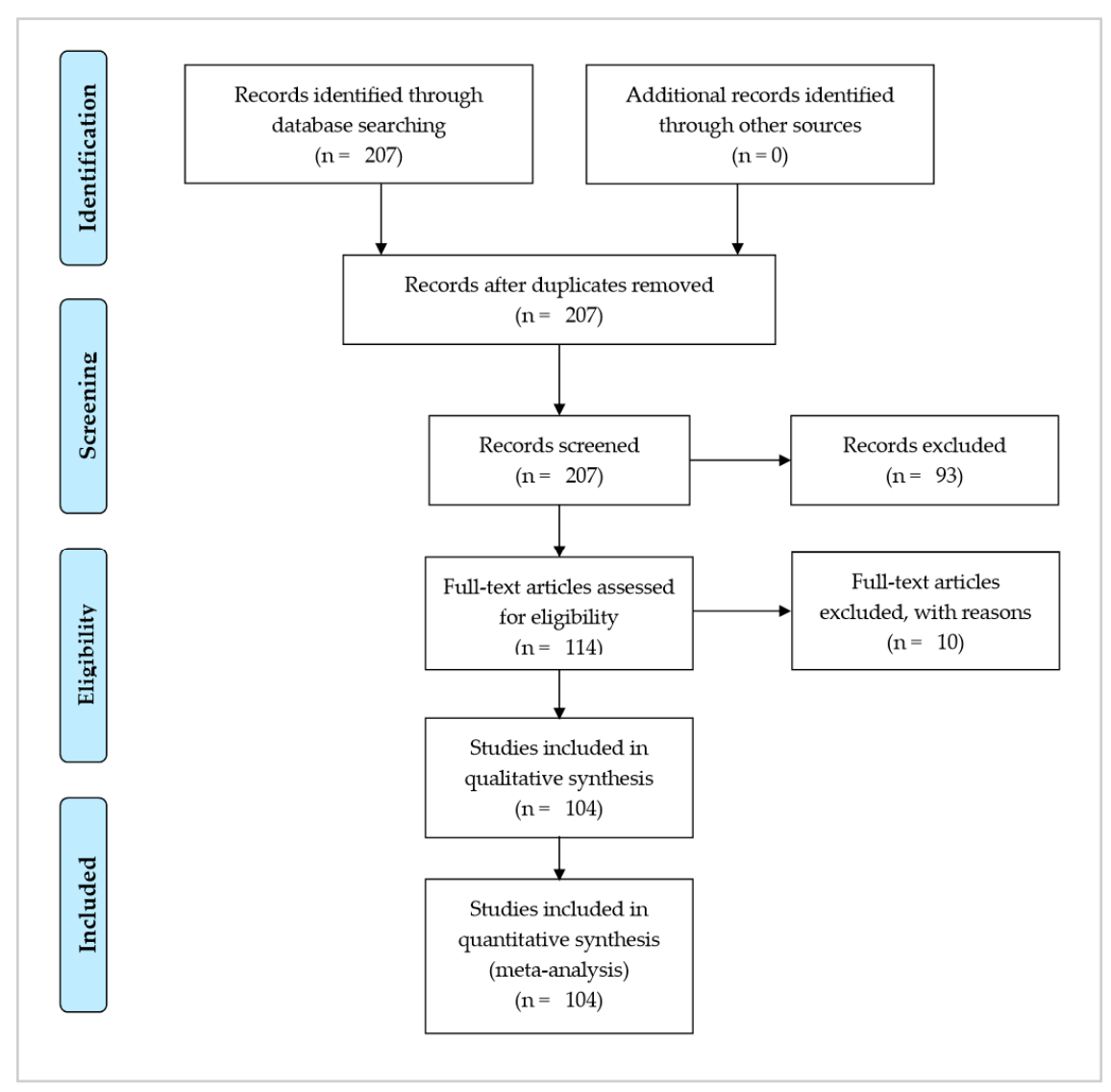

Figure 1. Flow diagram of studies included in the review based on PRISMA (Preferred Reporting Items for Systematic Reviews and Meta-Analyses) protocol.

\subsection{Description of the Final Set}

Considering the descriptive data from the final set of papers, we were able to analyze the trends of studies conducted on recent patterns of consumers' sustainable habits and practices. Figure 2 provides information on the number of articles published since 2016, showing a slight increase in 2019 to a peak of 28 articles. The assumption of increasing academic curiosity remains to be confirmed in the coming years. Considering that the present search started in March 2020, data for 2020 were only partial, but if the trend of the first quarter of the year is confirmed (8 published articles), more than 30 studies on this topic may be published in 2020 .

Table 1 shows that publications on this topic in the last five years mainly appeared in Sustainability (Switzerland) (12\% of papers), followed by the Journal of Cleaner Production ( $11 \%$ of papers), and Appetite and British Food Journal ( $6 \%$ of papers each). The other journals registered inferior numbers of retrieved articles. Such information could be helpful for future researchers interested in deepening the topic. 


\begin{tabular}{|lllll|}
\hline 30 & 19 & 25 & 24 & 28 \\
20 & 19 & & & \\
10 & 2016 & 2017 & 2018 & 2019 \\
\hline
\end{tabular}

Figure 2. Numbers of publications per year. Please note that the remaining eight articles were published in 2020.

Table 1. Summary of journals with the highest number of published papers.

\begin{tabular}{lc}
\hline \multicolumn{1}{c}{ Journal } & \% of Published Articles \\
\hline Sustainability (Switzerland) & $12 \%$ \\
Journal of Cleaner Production & $11 \%$ \\
Appetite & $6 \%$ \\
British Food Journal & $6 \%$ \\
\hline
\end{tabular}

As noted above, we encoded the academic field of each journal using the web source www. scimagojr.com, attributing multiple codes if applicable - that is, if a journal was classified with more than one academic field. Table 2 offers an overview of the number of publications for academic fields, basing on the publishing journal, distributed per year. Overall, we can note a predominance of Business, Management and Accounting and of Environmental Science and Forestry, which retrieved almost $40 \%$ of the total number of articles. Next were Social Science and Energy, with 33\% and $28 \%$ of studies, respectively. It is interesting to notice the trend over the years (Figure 3). In particular, papers published in journals belonging to the Social Science field are increasing, reaching a peak of $54 \%$ of studies published in 2019. On the other hand, the number of studies on journal belonging to Business, Management, Accounting academic field is getting lower.

Table 2. List of encoded academic fields of journals to which the selected papers belong.

\begin{tabular}{lc}
\hline \multicolumn{1}{c}{ Academic Field } & \% on Total Articles \\
\hline Business, management, accounting & $38 \%$ \\
Environmental science and forestry & $37 \%$ \\
Social science & $32 \%$ \\
Multidisciplinary & $27 \%$ \\
Energy & $23 \%$ \\
Agriculture and biological science & $18 \%$ \\
\hline
\end{tabular}

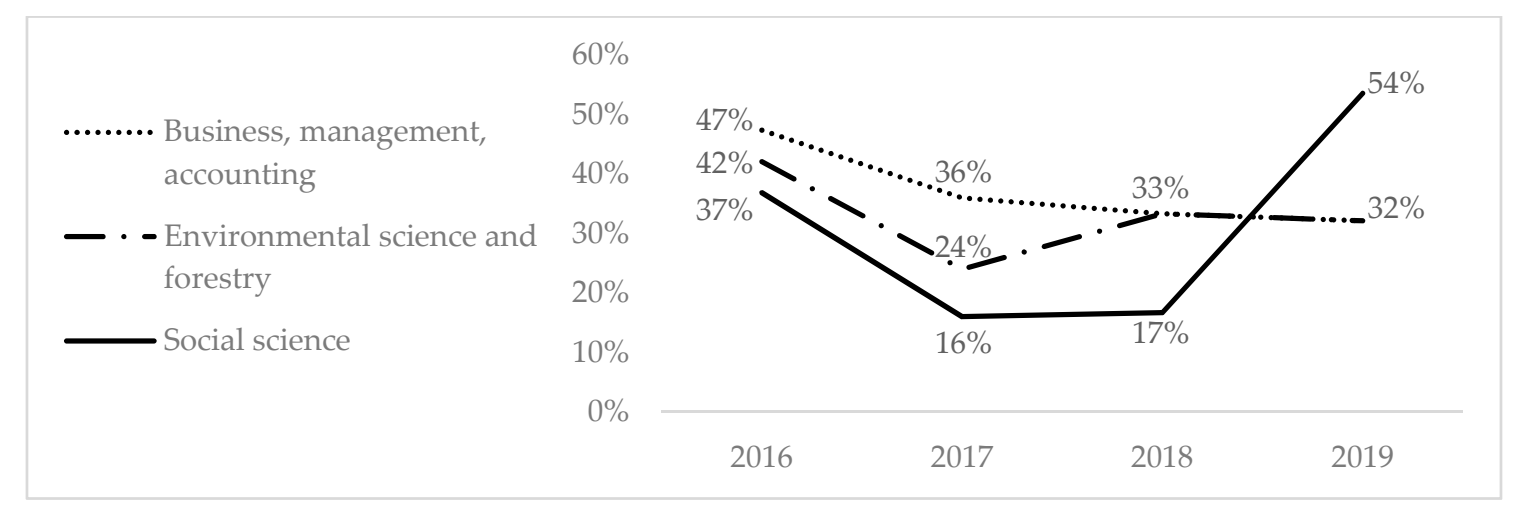

Figure 3. Time trends of the most frequent academic fields of journals from 2016 to 2019. 
Next, a cross-cultural perspective allowed us to further explore the findings. Indeed, different cultural contexts could influence and characterize consumers' trends of sustainable behaviors and practices, as well as academic curiosity. Looking at the geographical context where the selected studies have been performed (Figure 4), results show a high predominance of research on the chosen topic in Europe (55\%). Zooming in, Italy shows the largest number of papers (14\% of studies), followed by Germany ( $9 \%$ of studies) and the United States ( $\%$ of studies).

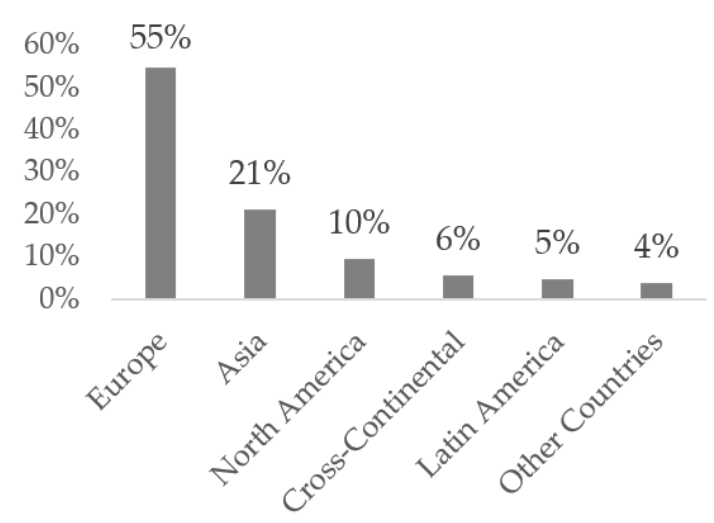

(a)

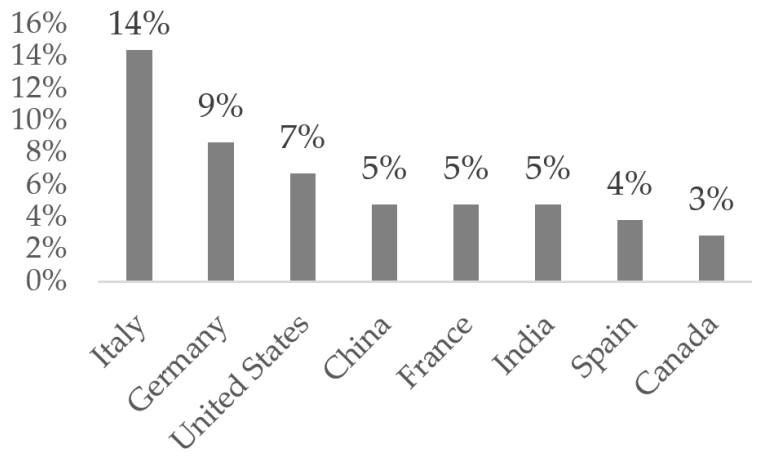

(b)

Figure 4. Number of publications by (a) macro-geographical area and (b) distributed among the most researched Countries.

With regard to research methodologies, the majority of studies employed a quantitative approach. Indeed, $69 \%$ of papers conducted quantitative research, whereas $17 \%$ of them chose mixed methods and the remaining $14 \%$ were qualitative studies.

As anticipated in the introduction, in our analysis the Triple Bottom Line was used to encode the selected studies [6]. Drawing from the three pillars of sustainability, we analyzed the papers searching for cues to the presence of environmental, social, and economic dimensions. Our findings reveal that $27 \%$ of the studies addressed more than one sustainability dimensions. Moreover, a great majority of articles dealt with the environmental side of sustainability, followed by social and economic dimensions $(88 \%, 24 \%$, and $22 \%$ of studies, respectively).

An additional categorization level was meant to distinguish the type of sustainable practice, habit, or aspect investigated. Taking inspiration from Hanss and Böhm [8], six different codes were identified. First, studies focused on exploring consumers' consumption and attractiveness of food produced in a sustainable way were differentiated from studies examining the consumption habits of other eco-friendly goods. The third code refers to sustainable practices, such as recycling, tourism, and mobility. Fourth, several articles delved into consumers' identity and values to understand their attitudes, beliefs, and motives regarding sustainability in general. The last two codes refer to resource preservation and local production.

As shown in Figure 5, most studies focused on sustainable practices, including household habits, recycling, reducing waste, sustainable tourism, and sharing economy. Next, many studies dealt with the food topic, investigating the habits, purchase behavior, and attractiveness of products that contain organic elements or that are produced through eco-friendly processes. The third most discussed issue comprised $21 \%$ of articles investigating consumers' behavior and attitude towards products realized in an environmentally friendly way (excluding food, which was considered separately). Next, studies exploring consumers' identity and values towards environment-related issues were found in $20 \%$ of papers. Less treated were the themes of resource preservation and local production $(4 \%$ and $3 \%$ of articles, respectively).

The last unit of analysis was the industry sector, as shown in Table 3. A "generic" code was used if no specific sector was reported (e.g., if sustainability was investigated in general terms). The food 
and beverage sector was the focus of more than $42 \%$ of all studies. The remaining articles were well distributed among the other categories.

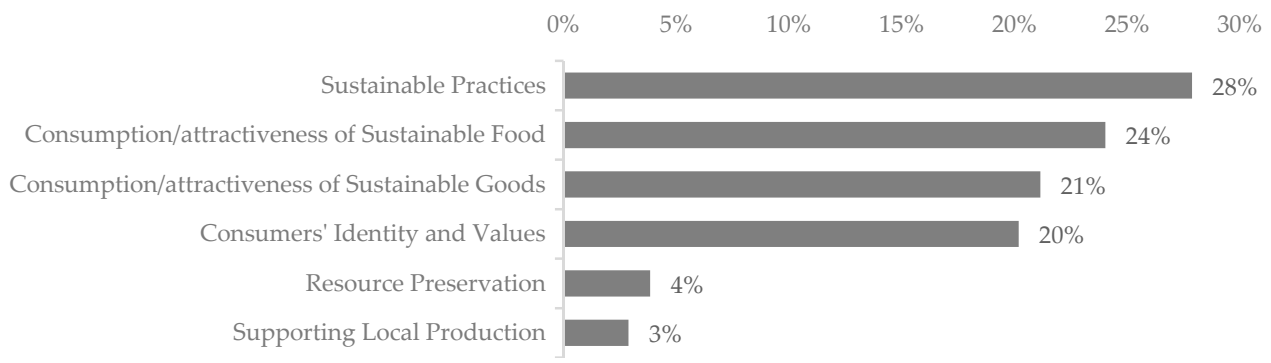

Figure 5. Classification of selected studies according to the sustainable aspect that was mainly investigated.

Table 3. Segmentation of papers by industry sector.

\begin{tabular}{|c|c|}
\hline Industry Sector & $\%$ of Papers \\
\hline Food/Beverage & $42 \%$ \\
\hline Generic & $20 \%$ \\
\hline Clothing & $8 \%$ \\
\hline Housing & $6 \%$ \\
\hline Commerce & $5 \%$ \\
\hline Transport/Mobility & $4 \%$ \\
\hline Technology & $4 \%$ \\
\hline Energy/Utilities (Water, Gas, Electricity) & $4 \%$ \\
\hline Services (Financial, Health, Communication, Professional) & $4 \%$ \\
\hline Tourism & $3 \%$ \\
\hline Luxury & $1 \%$ \\
\hline
\end{tabular}

To sum up, these findings show that the majority of papers explore the environmental impact of sustainability, with a preference for investigating sustainable practices and consumer appeal of eco-friendly food products. This is in line with the top-cited studies, as shown in Table 4 . Among them, $45 \%$ of studies investigated specific sustainable practices-such as recycling in Echegaray and Hansstein [25] and car-sharing in Wilhelms et al. [26], followed by exploring sustainable food consumption, like in Hoek et al. [27] and Thøgersen [28]. In addition, 8 out of the 11 top-cited papers took into account the environmental dimension of sustainability, overlooking social and economic aspects. Although research in this field is mostly related to the ecological aspect, cues from this first descriptive analysis of the articles suggest that the social perspective of sustainability is also recently taking hold.

\subsection{Specificity Analysis}

Using the software T-LAB, an initial specificity analysis was performed on all key lemmas and words present in the corpus, considering abstracts and titles of selected papers. As above mentioned, a lemma represents the dictionary form of a set of words, labeled in T-LAB according to linguistic criteria or by dictionaries and semantic grids customized by the authors [23]. Words and lemmas that occurred more than the minimum threshold and with the highest chi-square values were included. The chi-square made it possible to detect the lexical units that are defined for over-using and under-using. The specificity analysis was conducted on three different subcorpi-that is, corpus subsets as defined by a categorical variable distinguishing among the three dimensions of sustainability. Therefore, the subcorpus categorized as 'Environmental Sustainability' was compared with the rest of the textual corpus. The same logic was applied to the other two dimensions, social and economic sustainability. Tables 5-7 show the words/lemmas that are used more frequently or less frequently in each subcorpus compared to the rest of available text. 
Table 4. List of the top 11 most-cited papers.

\begin{tabular}{|c|c|c|c|c|}
\hline Title & Author(s) & Journal Title & $\begin{array}{c}\text { Year of } \\
\text { Publication }\end{array}$ & $\begin{array}{l}\text { Number of } \\
\text { Citation }\end{array}$ \\
\hline $\begin{array}{l}\text { Assessing the intention-behavior gap in } \\
\text { electronic waste recycling: The case of Brazil }\end{array}$ & Echegaray F., Hansstein F.V. & $\begin{array}{l}\text { Journal of Cleaner } \\
\text { Production }\end{array}$ & 2017 & 60 \\
\hline $\begin{array}{l}\text { Shrinking the food-print: A qualitative study } \\
\text { into consumer perceptions, experiences and } \\
\text { attitudes towards healthy and environmentally } \\
\text { friendly food behaviors }\end{array}$ & $\begin{array}{l}\text { Hoek A.C., Pearson D., James } \\
\text { S.W., Lawrence M.A., Friel S. }\end{array}$ & Appetite & 2017 & 55 \\
\hline $\begin{array}{l}\text { The effects of environmental and luxury beliefs } \\
\text { on intention to patronize green hotels: the } \\
\text { moderating effect of destination image }\end{array}$ & Line N.D., Hanks L. & $\begin{array}{l}\text { Journal of } \\
\text { Sustainable } \\
\text { Tourism }\end{array}$ & 2016 & 31 \\
\hline $\begin{array}{l}\text { Sustainable food consumption in the nexus } \\
\text { between national context and private lifestyle: } \\
\text { A multi-level study }\end{array}$ & Thøgersen J. & $\begin{array}{l}\text { Food Quality and } \\
\text { Preference }\end{array}$ & 2017 & 26 \\
\hline $\begin{array}{l}\text { Self-consumption with PV + Battery systems: } \\
\text { A market diffusion model considering individual } \\
\text { consumer behavior and preferences }\end{array}$ & Klingler A.-L. & Applied Energy & 2017 & 25 \\
\hline $\begin{array}{l}\text { Food choice motives when purchasing in organic } \\
\text { and conventional consumer clusters: Focus on } \\
\text { sustainable concerns (the nutrinet-santé } \\
\text { cohort study) }\end{array}$ & $\begin{array}{l}\text { Baudry J., Péneau S., Allès B., } \\
\text { Touvier M., Hercberg S., Galan } \\
\text { P., Amiot M.-J., Lairon D., } \\
\text { Méjean C., Kesse-Guyot E. }\end{array}$ & Nutrients & 2017 & 23 \\
\hline
\end{tabular}

Table 5. Specificity analysis: more/less frequently used words in papers investigating the environmental dimension of sustainability.

\begin{tabular}{|c|c|c|c|c|}
\hline \multicolumn{5}{|c|}{ More Frequently Used Words/Lemmas (Linked to Environmental Sustainability) } \\
\hline Word & Subcorpus & Total & $x^{2}$ & $(p)$ \\
\hline Food & 245 & 248 & 20.01 & $<0.001$ \\
\hline Purchase & 76 & 78 & 4.29 & 0.038 \\
\hline Product & 132 & 138 & 4.16 & 0.041 \\
\hline \multicolumn{5}{|c|}{ Less Frequently Used Words/Lemmas (Linked to Environmental Sustainability) } \\
\hline Word & Subcorpus & Total & $x^{2}$ & $(p)$ \\
\hline Bank & 0 & 13 & -126.01 & $<0.001$ \\
\hline Ethical & 9 & 23 & -72.08 & $<0.001$ \\
\hline Mobile & 2 & 10 & -58.85 & $<0.001$ \\
\hline Customer & 3 & 11 & -52.10 & $<0.001$ \\
\hline Social & 61 & 85 & -36.02 & $<0.001$ \\
\hline Ethic & 6 & 13 & -30.35 & $<0.001$ \\
\hline Market & 51 & 69 & -22.92 & $<0.001$ \\
\hline Belief & 7 & 13 & -20.76 & $<0.001$ \\
\hline Article & 6 & 11 & -16.90 & $<0.001$ \\
\hline Research & 66 & 84 & -14.55 & $<0.001$ \\
\hline Strategy & 15 & 22 & -13.10 & $<0.001$ \\
\hline German & 5 & 9 & -13.06 & $<0.001$ \\
\hline Focus & 24 & 33 & -12.52 & $<0.001$ \\
\hline Culture & 16 & 23 & -12.06 & $<0.001$ \\
\hline Motivate & 6 & 10 & -11.07 & $<0.001$ \\
\hline Qualitative & 14 & 20 & -10.06 & 0.001 \\
\hline Value & 49 & 62 & -9.91 & 0.001 \\
\hline
\end{tabular}


Table 5. Cont.

\begin{tabular}{lcccc}
\hline \multicolumn{5}{c}{ Less Frequently Used Words/Lemmas (Linked to Environmental Sustainability) } \\
\hline Word & Subcorpus & Total & $\chi^{\mathbf{2}}$ & $(p)$ \\
\hline Technology & 19 & 26 & -9.47 & 0.002 \\
Wine & 9 & 13 & -7.03 & 0.008 \\
Society & 9 & 13 & -7.03 & 0.008 \\
Individual & 40 & 50 & -6.70 & 0.009 \\
\hline
\end{tabular}

Note: More (less) frequently used words are words that are used more (less) often in a given subcorpus when compared to the total. Words in bold are the most relevant for data interpretation. All values are statistically significant at $p<0.05$.

Table 6. Specificity analysis: more/less frequently used words in papers investigating the social dimension of sustainability.

\begin{tabular}{|c|c|c|c|c|}
\hline \multicolumn{5}{|c|}{ More Frequently Used Words/Lemmas (Linked to Social Sustainability) } \\
\hline Word & Subcorpus & Total & $x^{2}$ & $(p)$ \\
\hline Ethical & 22 & 23 & 60.19 & $<0.001$ \\
\hline Social & 49 & 85 & 47.27 & $<0.001$ \\
\hline Fashion & 18 & 23 & 34.09 & $<0.001$ \\
\hline Regional & 13 & 14 & 33.75 & $<0.001$ \\
\hline Ethic & 12 & 13 & 30.83 & $<0.001$ \\
\hline Oil & 17 & 24 & 26.29 & $<0.001$ \\
\hline Citizenship & 10 & 11 & 25.00 & $<0.001$ \\
\hline Sustainability & 48 & 103 & 24.85 & $<0.001$ \\
\hline Dimension & 19 & 29 & 24.79 & $<0.001$ \\
\hline Conventional & 11 & 15 & 18.27 & $<0.001$ \\
\hline Mobile & 8 & 10 & 15.79 & $<0.001$ \\
\hline Palm & 12 & 19 & 14.37 & $<0.001$ \\
\hline Customer & 8 & 11 & 13.05 & $<0.001$ \\
\hline Focus & 17 & 33 & 11.97 & $<0.001$ \\
\hline Information & 21 & 45 & 10.85 & $<0.001$ \\
\hline Dietary & 8 & 13 & 9.00 & 0.002 \\
\hline View & 8 & 13 & 9.00 & 0.002 \\
\hline Article & 7 & 11 & 8.52 & 0.003 \\
\hline Chinese & 6 & 9 & 8.12 & 0.004 \\
\hline Socially & 6 & 9 & 8.12 & 0.004 \\
\hline \multicolumn{5}{|c|}{ Less Frequently Used Words/Lemmas (Linked to Social Sustainability) } \\
\hline Word & Subcorpus & Total & $x^{2}$ & $(p)$ \\
\hline Consumption & 34 & 234 & -14.91 & $<0.001$ \\
\hline Meat & 0 & 40 & -13.66 & $<0.001$ \\
\hline Waste & 1 & 45 & -12.80 & $<0.001$ \\
\hline Variable & 0 & 25 & -8.52 & 0.003 \\
\hline Household & 0 & 25 & -8.52 & 0.003 \\
\hline Eat & 0 & 24 & -8.18 & 0.004 \\
\hline Attitude & 13 & 98 & -7.66 & 0.005 \\
\hline Base & 3 & 41 & -7.09 & 0.007 \\
\hline Public & 0 & 19 & -6.47 & 0.010 \\
\hline Recycle & 0 & 19 & -6.47 & 0.010 \\
\hline Increase & 2 & 32 & -6.20 & 0.012 \\
\hline Laundry & 0 & 18 & -6.13 & 0.013 \\
\hline Energy & 5 & 49 & -5.98 & 0.014 \\
\hline Reduce & 1 & 24 & -5.71 & 0.016 \\
\hline Beef & 0 & 15 & -5.11 & 0.023 \\
\hline Demographic & 1 & 22 & -5.05 & 0.024 \\
\hline Environmental & 19 & 116 & -5.01 & 0.025 \\
\hline
\end{tabular}

Note: More (less) frequently used words are words that are used more (less) often in a given subcorpus when compared to the total. Words in bold are the most relevant for data interpretation. All values are statistically significant at $p<0.05$. 
Table 7. Specificity analysis: more/less frequently used words in papers investigating Economic dimension of sustainability.

\begin{tabular}{|c|c|c|c|c|}
\hline \multicolumn{5}{|c|}{ More Frequently Used Words/Lemmas (Linked to Economic Sustainability) } \\
\hline Word & Subcorpus & Total & $x^{2}$ & $(p)$ \\
\hline Oil & 22 & 24 & 76.31 & $<0.001$ \\
\hline Motive & 24 & 31 & 63.24 & $<0.001$ \\
\hline Regional & 13 & 14 & 45.96 & $<0.001$ \\
\hline Dimension & 15 & 29 & 17.96 & $<0.001$ \\
\hline Economic & 12 & 22 & 16.16 & $<0.001$ \\
\hline Dietary & 8 & 13 & 13.82 & $<0.001$ \\
\hline Sustainability & 35 & 103 & 12.31 & $<0.001$ \\
\hline Evidence & 6 & 9 & 12.08 & $<0.001$ \\
\hline Generation & 6 & 9 & 12.08 & $<0.001$ \\
\hline Local & 13 & 28 & 12.00 & $<0.001$ \\
\hline Innovation & 8 & 14 & 11.88 & $<0.001$ \\
\hline Transition & 8 & 14 & 11.88 & $<0.001$ \\
\hline Business & 11 & 23 & 10.93 & $<0.001$ \\
\hline Development & 10 & 25 & 6.11 & 0.013 \\
\hline Economy & 7 & 18 & 3.91 & 0.047 \\
\hline \multicolumn{5}{|c|}{ Less Frequently Used Words/Lemmas (Linked to Economic Sustainability) } \\
\hline Word & Subcorpus & Total & $x^{2}$ & $(p)$ \\
\hline Meat & 0 & 40 & -10.17 & 0.001 \\
\hline Perceive & 1 & 35 & -6.55 & 0.010 \\
\hline Variable & 0 & 25 & -6.34 & 0.011 \\
\hline Household & 0 & 25 & -6.34 & 0.011 \\
\hline Eat & 0 & 24 & -6.09 & 0.013 \\
\hline Ethical & 0 & 23 & -5.83 & 0.015 \\
\hline Fashion & 0 & 23 & -5.83 & 0.015 \\
\hline
\end{tabular}

Note: More (less) frequently used words are words that are used more (less) often in a given subcorpus when compared to the total. Words in bold are the most relevant for data interpretation. All values are statistically significant at $p<0.05$.

In studies dealing with the environmental dimension of sustainability, researchers use the words 'food', 'purchase', and 'product' particularly frequently, suggesting a strong focus on consumers' habits and practices connected to shopping behaviors (Table 5). In addition, almost $50 \%$ of papers present in this subcorpus presented research conducted in the food/beverage sector, investigating consumers' attractiveness towards products produced using eco-friendly practices. On the other hand, the less frequent use of words like 'bank', 'ethical', 'social', and 'market' reinforces the distinction between the environmental dimension and social and economic aspects of sustainability.

Table 6 shows the more frequently used words and lemmas in the subcorpus exploring the social dimension of sustainability. In this case, the more frequent use of words like 'ethical', 'social', 'regional', and 'citizenship' seems to indicate a reference to a communitarian and collective dimension, whose spotlight is the collective rather than the individual. By contrast, words like 'consumption', 'meat', 'waste', and 'household' were significantly less used than in the rest of the texts, suggesting less attention towards individual practices and behaviors.

Last, with regard to the economic dimension of sustainability, the analysis demonstrated a more frequent use of words linked to financial profitability and the impact on local economy-words such as 'economic', 'regional', 'local', and 'business' (Table 7). On the other side, it is interesting to notice that the less frequently used words for economic sustainability are partially the same as those that less connote social sustainability (Table 6), suggesting a proximity between them.

\subsection{Correspondence Analysis}

Correspondence analysis was performed to map the relationships between words and categorical variables. This technique made it possible to organize data in thematic clusters represented in a 
two-dimensional chart. The following variables were actively used in the analysis: year of publication, industry sector, explored habit and practice, methods, and dimensions of sustainability. For a better understanding, 'active' variables are those that take part in the construction of factorial axes in the correspondence analysis [23]. First, we examined the words, lemmas, and variables that characterized the factorial poles of the two resulting factors, identifying the underlying dimensions. Tables 8 and 9 illustrate the lemmas which feature the two factors, whereas Figure 6 shows how the investigated variables position on the two-dimensional chart.

Factor 1 (horizontal axis, explained inertia $=9.96 \%$ ) distinguishes among the three dimensions of the Triple Bottom Line. On the positive pole we can find the social and economic dimensions of sustainability, while on the opposite edge the ecological aspect emerges. Indeed, the positive pole-which refers to social and economic dimensions of sustainability-features words like 'bank', 'tourism', 'ethical', 'identity', and 'customer' (Table 8). Moreover, the period 2019-2020 characterizes this side of Factor 1, whereas the period between 2016 and 2018 connotes the opposite edge (as shown in Figure 6). From a methodological point of view, we can find the presence of qualitative methods on the right side, whereas quantitative research appears on the opposite side. Focusing on the negative pole, the environmental impact of sustainability holds a strong position, linking aspects like consumers' attractiveness to eco-friendly food products and resource preservation. Words like 'meat', 'food', 'waste', and 'energy' characterize this pole.

Table 8. Lemmas featured on horizontal axis, distinguishing among sustainable dimensions.

\begin{tabular}{lcc}
\hline \multicolumn{3}{c}{ Positive Pole of Factor 1 (Horizontal Axis) } \\
\hline Feature & Type & V-Test \\
\hline Bank & LEMMA & 8.94 \\
Ethical & LEMMA & 7.52 \\
Social & LEMMA & 6.99 \\
Handicraft & LEMMA & 6.10 \\
Regional & LEMMA & 6.00 \\
Customer & LEMMA & 5.44 \\
Globalization & LEMMA & 5.19 \\
Mobile & LEMMA & 5.02 \\
Tourism & LEMMA & 4.89 \\
Ethic & LEMMA & 4.83 \\
Ethnocentrism & LEMMA & 4.38 \\
Hotel & LEMMA & 4.31 \\
Oil & LEMMA & 4.22 \\
Destination & LEMMA & 4.21 \\
Identity & LEMMA & 4.18 \\
\hline Negative pole of Factor 1 (Horizontal Axis) \\
\hline Feature & Type & V-Test \\
\hline Meat & LEMMA & -6.30 \\
Food & LEMMA & -5.77 \\
Waste & LEMMA & -4.40 \\
Public & LEMMA & -4.31 \\
Beef & LEMMA & -4.09 \\
Energy & LEMMA & -4.02 \\
Household & LEMMA & -3.82 \\
Dilemma & LEMMA & -3.70 \\
Aquaculture & LEMMA & -3.69 \\
Eat & LEMMA & -3.60 \\
\hline
\end{tabular}

Note: Words in bold are the most relevant for data interpretation. V-Test is a statistical measure used to facilitate the interpretation of factor polarities. 
Table 9. Lemmas and variables featured on vertical axis, differentiating the research spotlight (food products vs other types of goods).

\begin{tabular}{|c|c|c|}
\hline \multicolumn{3}{|c|}{ Positive Pole of Factor 2 (Vertical Axis) } \\
\hline Feature & Type & V-Test \\
\hline Food & LEMMA & 13.17 \\
\hline Regional & LEMMA & 9.16 \\
\hline Local & LEMMA & 7.31 \\
\hline Organic & LEMMA & 6.42 \\
\hline Eater & LEMMA & 6.28 \\
\hline Ethnocentrism & LEMMA & 6.28 \\
\hline Virgin & LEMMA & 5.73 \\
\hline Olive & LEMMA & 5.54 \\
\hline Motive & LEMMA & 5.38 \\
\hline Score & LEMMA & 5.23 \\
\hline Dietary & LEMMA & 4.86 \\
\hline Meat & LEMMA & 4.85 \\
\hline Handicraft & LEMMA & 4.61 \\
\hline Production & LEMMA & 4.57 \\
\hline Dimension & LEMMA & 4.52 \\
\hline Opinion & LEMMA & 4.42 \\
\hline Chocolate & LEMMA & 4.33 \\
\hline \multicolumn{3}{|c|}{ Negative Pole of Factor 2 (Vertical Axis) } \\
\hline Feature & Type & V-Test \\
\hline Laundry & LEMMA & -7.71 \\
\hline Fashion & LEMMA & -6.45 \\
\hline Washing & LEMMA & -6.12 \\
\hline Product-Service-System & LEMMA & -6.01 \\
\hline Energy & LEMMA & -5.85 \\
\hline Clothes & LEMMA & -5.19 \\
\hline Clean & LEMMA & -5.06 \\
\hline Wash & LEMMA & -4.67 \\
\hline Detergent & LEMMA & -4.52 \\
\hline Bangkok & LEMMA & -4.48 \\
\hline Cotton & LEMMA & -4.39 \\
\hline Domestic & LEMMA & -4.36 \\
\hline Wool & LEMMA & -4.27 \\
\hline Recycle & LEMMA & -4.14 \\
\hline
\end{tabular}

Words in bold are the most relevant for data interpretation. V-Test is a statistical measure used to facilitate the interpretation of factor polarities.

Factor 2 (vertical axis, explained inertia $=8.25 \%$ ) does not distinguish between sustainable dimensions, whereas it refers to the types of products and practices that are in the spotlight of the selected studies. Indeed, the top side is composed of the industry sector food and beverage, together with a focus on consumers' habits regarding food produced in a sustainable way and supporting local production (Figure 6). Additional cues enforce the idea that this pole concerns food products, including words like 'food', 'regional', 'local', 'organic', 'ethnocentrism', and 'handicraft' (Table 9). On the bottom side, we can instead find words/lemmas like 'laundry', 'fashion', 'washing', 'energy', and 'clothes'. Looking at the industry sectors, housing, clothing, technology, and luxury characterize this pole, together with a focus on sustainable practices and the consumption of sustainable products, excluding food (Figure 6).

In sum, our findings suggest that the vertical axis refers to the products and practices targeted by selected research, with food products on the one side and other type of goods on the bottom side; the horizontal axis instead distinguishes between environmental dimension of sustainability on the left side and economic and social dimensions on the right one. As shown in Figure 6, in the top left quadrant we can find food-related consumption, with a focus on environmental dimension; the bottom left quadrant is featured as well by a predominance of the ecological aspect, targeting 
consumers' practices in industry sectors such as housing and energy. Looking at the right part of the two-dimensional chart, in the top right quadrant social and economic dimensions can be found, close-up to the commercial sector. Last, in the bottom right quadrant we can detect habits related to goods produced in a sustainable way in sectors such as clothing and luxury.

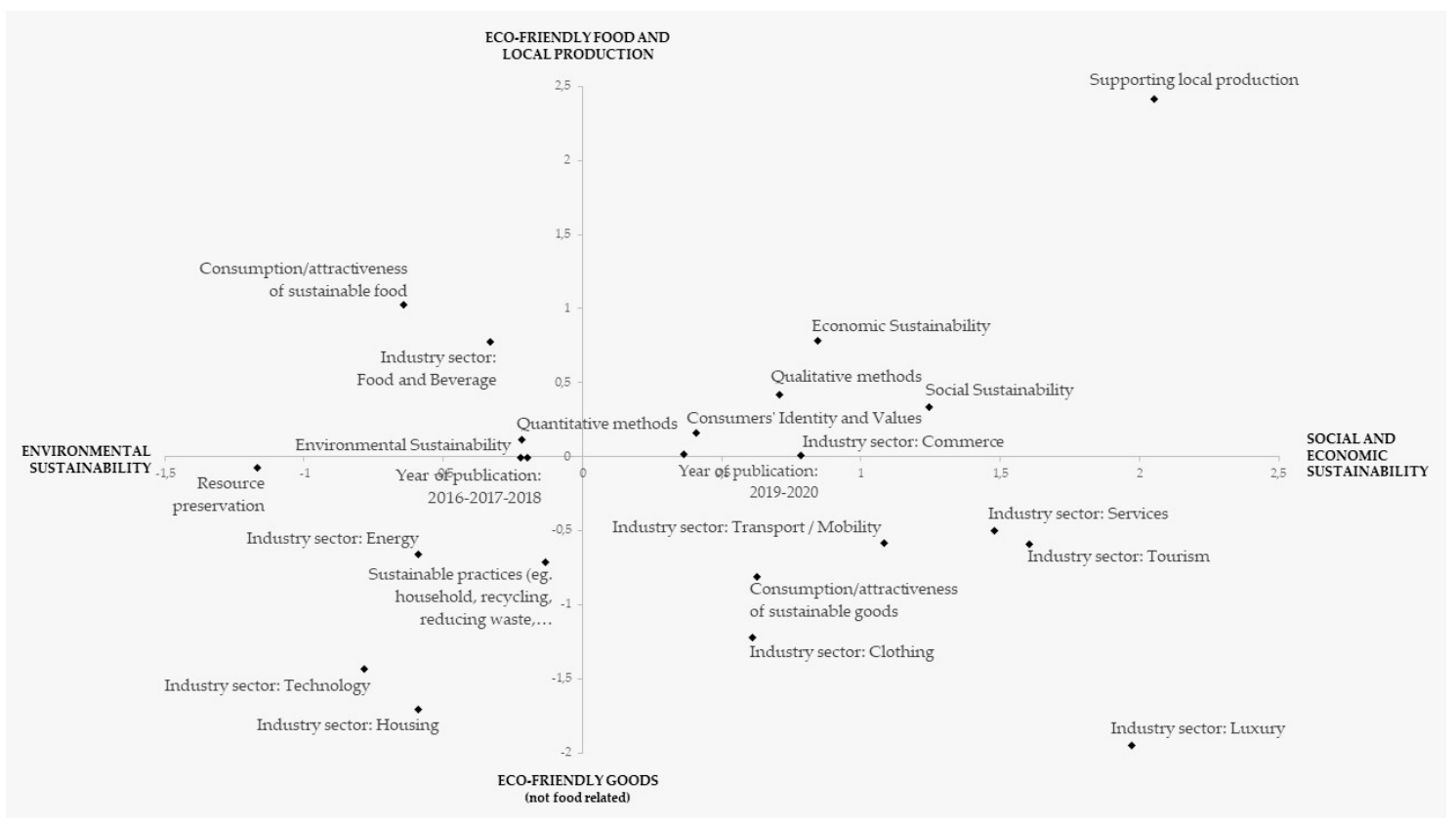

Figure 6. Positioning of variables on the two-dimensional chart, delimited by Factor 1 and Factor 2.

As written above, we also conducted a cluster analysis to map the variables and words and achieve deeper insights on the papers included in the review. Four clusters emerged, including 37\%, $27 \%, 30 \%$, and $6 \%$ of the whole corpus, respectively, as shown in Table 10 .

Table 10. Percentage of the corpus included in each cluster.

\begin{tabular}{lc}
\hline \multicolumn{1}{c}{ Cluster } & $\%$ \\
\hline CLUSTER 1: Consumption of organic products and eco-friendly food & $37.02 \%$ \\
CLUSTER 2: Consumers' practices related to fashion and clothing & $27.02 \%$ \\
CLUSTER 3: Sustainable practices related to household and recycling & $29.65 \%$ \\
CLUSTER 4: Ethical practices linked to tourism, commerce, and other services & $06.32 \%$ \\
TOTAL & $100.00 \%$ \\
\hline
\end{tabular}

Cluster 1, 'consumption of organic products and eco-friendly food', represents the biggest group. Looking at the variables and words composing this cluster, we can observe the almost homogeneous presence of the topic concerning consumers' interest towards environmentally sound food products, as well as words like 'food', 'meat', 'organic', 'diet', 'healthy', and 'beef'. The environmental dimension of sustainability also seems to describe this cluster. Considering that $78 \%$ of the corpus encoded as the food and beverage sector is included in Cluster 1, it is feasible to assume that this cluster refers to consumers' habits, behaviors, and attitudes towards organic products and food realized in an environmentally friendly way.

Cluster 2, 'consumers' practices related to fashion and clothing', is characterized by consumers' attractiveness towards eco-friendly products and words/lemmas such as 'fashion', 'apparel', and 'cotton'. The social dimension of sustainability is particularly typical of this cluster, which includes almost $53 \%$ of the corpus encoded with such variables. If we consider industrial sectors, Cluster 2 is more varied, collecting luxury, clothing, housing, and mobility. To summarize, it refers to consumers' practices related to fashion and clothing, especially targeting their social impact. 
Moving to Cluster 3, 'sustainable practices related to household and recycling', it is characterized by words like 'energy', 'recycle', and 'household' and by the convergence of the industry sectors energy and utilities. We can also detect the reference to sustainable practices and consumers' identity and values that feature in Cluster 3, together with the environmental side of sustainability. Therefore, we can conclude that it refers to consumers' sustainable practices related to household and recycling.

Lastly, the fourth cluster, 'ethical practices linked to tourism, commerce, and other services', explains the lowest percentage of variance. We can find words like 'ethical' and 'identity', as well as concepts referring to the service sector, like 'hotel', 'mobile', 'tourism', and 'car-sharing'. As we look at the sectors converging in this cluster, we can find tourism, commerce, and services. It is interesting to note that the environmental side of sustainability is less prominent in this cluster, which is more characterized by the economic dimension.

To sum up, clear differences characterize the four resulting groups. Figure 7 shows the positioning of the four clusters on the two-dimensional chart defined by factors identified at the beginning of Section 3.3. Cluster 1 mainly gathers consumers' interest and habits towards organic products and food produced in an environmentally sound way, and it is located in the quadrant characterized by the environmental dimension of sustainability and consumers' attitude toward eco-friendly food. In the opposite quadrant, marked by a focus on consumers' practices and a predominance of social and economic aspects of sustainability, we can find Cluster 2, which gathers industrial sectors targeting 'Fashion' and 'Clothing', and the social dimension of sustainability. With regard to Cluster 3, its positioning features a prevalence of the environmental side of sustainability, as well as a focus on consumers' sustainable practices related to households and recycling. Lastly, Cluster 4, the smallest group, is positioned on the right side of horizontal axis and corresponds to a spotlight on ethical practices in sectors such as tourism and commerce, with a marked economic perspective.

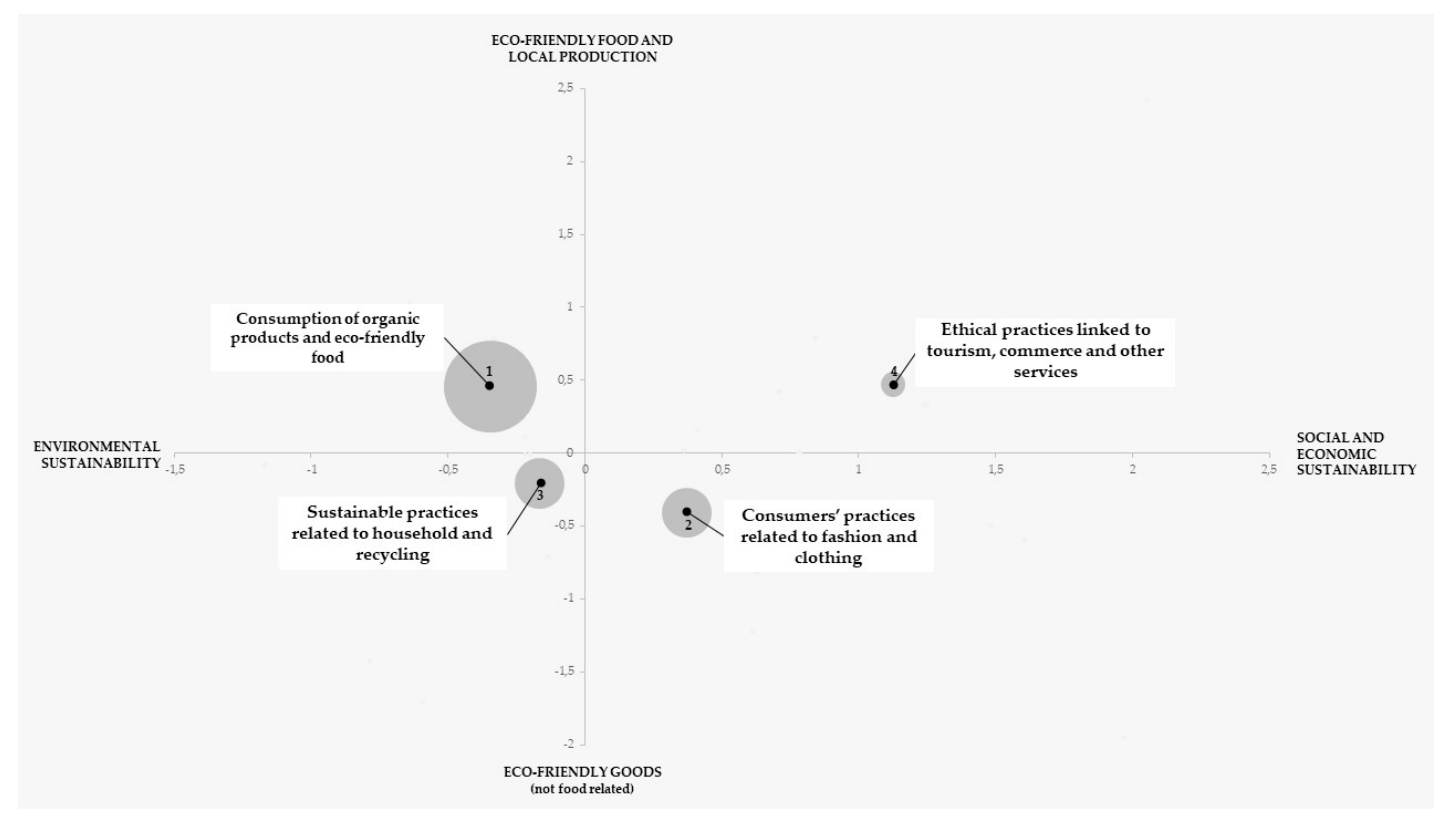

Figure 7. Positioning of clusters on the two-dimensional chart, delimited by Factor 1 and Factor 2.

\section{Discussion}

This paper offers a systematic review of research exploring recent trends in consumers' sustainable practices over the period of 2016-2020. Our study provides an innovative perspective, since the employed lexicographical analysis methodology allowed for delving into the contents and features of selected papers without being limited to the descriptive level. The aim was to explore recent patterns of sustainable consumption grasping the perspective of consumers in order to detect trends characterizing the research on sustainable behaviors over the last five years. 
Our findings suggest that research on consumers and sustainability is solid, covering a wide range of topics that have been investigated with different methodologies. Indeed, an increase in 2019 of papers dedicated to trends of consumers' sustainable behaviors highlights a growing curiosity towards this theme. Different topics have caught the attention of researchers, from sustainable practices like household behavior and the circular economy to consumers' attractiveness to eco-friendly products. This variety of investigated topics is confirmed by past reviews, whose scope is quite heterogeneous (e.g., sharing economy in Agarwal and Steinmetz [11]; sustainable tourism in Hall et al. [13]; attractiveness of sustainable features of products in Bunga Bangsa and Schlegelmilch [15]; food and beverage consumption in Sanchez-Sabate and Sabaté [16]).

Our study shows a predominance of research focused on the food and beverage industry sector that accounts for more than $42 \%$ of all selected studies, in line with the top-cited papers. The predominance of research in some specific sectors is in line with the results of the 'European Environmental Impact of Products' Project published in 2005 [29], in which the key sectors for environmental impacts were confirmed to be food and drink, housing, and transport. There is less variety in the methodological perspectives, as the quantitative approach dominates in the majority of papers of the present review.

An interesting piece of evidence is the predominance of studies exploring the environmental side of sustainability, overlooking social and economic dimensions. Assuming that sustainable consumption is a complex concept, past researchers have already advocated for a more holistic approach to this topic [2]. Extensive emphasis has already been placed on the environmental impact, together with a predominant interest in the aspect of purchasing rather than the whole cycle of consumption and production [1,5]. At the same time, sustainability marketing research also tends to focus only on specific dimensions rather than on sustainability as a whole [5]. In addition, the vast majority of past reviews focused mainly on the environmental dimension, although there are some exceptions [15,19]. In most cases, the dimensions of sustainability are not even a level of analysis; thus, it is difficult to clearly depict a distinction among the investigated articles. Also, considering the exceptions, both Bunga Bangsa and Schlegelmilch [15] and Amarando et al. [19] reported a strong predominance of studies exploring environmental aspects over social or economic aspects.

However, different cues emerging from our review suggest a transition to an increasing interest in the social perspective of sustainability. Indeed, the trend over years of published searches exploring the three dimensions of sustainability shows that, besides a constantly growing interest in environmental aspects, the social impact of sustainable practices also seems to be increasingly in the spotlight. In addition, papers published in journals belonging to the Social Science academic field increased in 2019, whereas publications in Business, Management, Accounting are decreasing.

Confirming the above-mentioned results, the lexicographical analysis showed the predominance of the 'consumption of organic products and eco-friendly food' cluster, characterized by a preference for the environmental dimension of sustainability. Nevertheless, while studies published between 2016 and 2018 appear on the same side of the chart, studies from 2019 emerge on the opposite side, placing them on the pole characterized by the social and economic dimensions of sustainability. On this side we can also find the clusters 'ethical practices linked to tourism, commerce, and other services' and 'consumers' practices related to fashion and clothing', again suggesting an interest in the social impact of consumers' practices.

\subsection{Research Agenda}

The results which emerged from the current analysis indicate some areas to be explored in the future research agenda. In the following paragraphs, different starting points are provided to stimulate additional research in the field of consumer's sustainable behavior.

First, sustainability depends not on a single factor but on multiple sets of factors that conjointly determine an impact on environmental, social, and economic preservation $[2,5,9]$. Our findings suggest that the social dimension of sustainability provides a more communitarian and collective dimension, whose spotlight is the collective rather than the individual. This is in line with Peattie and Collins [1], 
demanding an in-depth analysis of the other two sides of sustainability with the aim of emphasizing the connections and highlighting the consequences of individual and collective behavior.

Then, looking at the 2030 Agenda for Sustainable Development and its 17 Sustainable Development Goals [4], further possibilities to broaden the research scope emerge. Indeed, some of the objectives identified by the United Nations Member States in 2015 seem to be unexplored lands. In particular, good health and well-being, gender equality, and promotion of peaceful and just societies and institutions are some of the less-treated themes from the perspective of consumers' practices.

A broader and more holistic perspective is therefore recommended, in the attempt to preserve the diversity of sustainability issues and to avoid overshadowing some of their facets [2,30]. In this context, fostering a deeper understanding of consumers would have a key role in reinforcing sustainable patterns of consumption in the long term [10]. Indeed, the ownership of sustainable consumption is not only up to producers, who transfer such responsibility to consumers from the moment of the purchase [31]. In addition, recent trends of sustainable practices seem to ask for a more active role of the consumer. Activities such as the sharing economy, sustainable tourism, and ethical banking imply a more active commitment and participation to favor sustainability, if compared to more passive consumers who purchase products looking for specific sustainable features. Thus, the responsible consumer embodies all the different facets of sustainable impacts, including environmental, social, and economic perspectives [2]. It is necessary to comprehend consumers' prospects to engage in and maintain sustainable behavior, looking at sustainability in its entirety. Topics dear to social sciences and psychology are key to deeply understanding sustainable practices from the actors' perspective and reaching a holistic conceptualization of sustainable behavior [2]. In such a framework, qualitative methods can be key instruments to gain a deeper understanding of consumers' perspective.

In addition, our study showed that research on new trends of sustainable consumption has predominantly been conducted in developed countries (e.g., Italy, Germany, and the United States, as shown in Figure 4). Future studies could deepen this topic in emerging countries and explore how consumption patterns differ between developed and developing countries.

Finally, results related to the present research study suggest the heterogeneous interest in the topic of sustainability that continues to evolve over time. This could be significant not only for scholars, but also for marketers and companies that could look at sustainable consumption with a broader perspective. For instance, it could be relevant to deepen how the emphasis on the three dimensions of sustainability is perceived by consumers, to study less explored areas of sustainable consumption, and finally, to adapt the proposal of services and products according to the current trends of consumers' sustainable behavior.

\subsection{Limitations}

Of course, our own research was not without limitations. First, we used a limited number of key words with the aim of specifically depicting papers investigating new trends of sustainable behavior with a focus on consumers. The same definition of sustainable consumption is fragmented, and future studies could widen the search keywords. Second, our search was limited to the Scopus database. Although Scopus is an exhaustive and broad source, future research could extend the search scope to other databases. Finally, from a methodological perspective, we respected the guidelines provided by the PRISMA statement for systematic reviews and meta-analysis, although future research could also refer to bibliometric indicators that would strengthen the quality of the research providing a normalization of bibliometric data [32].

To sum up, at the present moment research on consumers and sustainability is strong and heterogeneous. However, some areas needing further investigation emerge. Future research should spotlight the less explored frameworks, looking at the economic and social sides of sustainability in a variety of contextual settings. At the same time, consumer-focused research should not forget to look at consumers' sustainable behavior as a whole and its impacts from the perspectives of planet, people, and profit. 
Author Contributions: All of the authors contributed to the conceptualization of this systematic review and data analysis. G.S. performed the selection of papers; the three authors screened and categorized the articles; G.S. and C.C. performed the data analysis with the software T-LAB; G.S. wrote the original draft. All of the authors reviewed and edited the original draft, and have read and approved the final manuscript. All authors have read and agreed to the published version of the manuscript.

Funding: This research received no external funding.

Conflicts of Interest: The authors declare no conflict of interest.

\section{Appendix A}

Box A1. Papers Included in the Review.

1. Abdelgalil M.S. Practices in using and handling household cleaning products in Egypt. Tenside Surfact Det. 2016, 53, 576-588. doi:10.3139/113.110452

2. Abdulrazak S., Quoquab F. Exploring Consumers' Motivations for Sustainable Consumption: A Self-Deterministic Approach. J. Int. Consum. Mark. 2018, 1, 14-28. doi:10.1080/08961530.2017.1354350

3. Afzal F., Yunfei S., Sajid M., Afzal F. Market sustainability: A globalization and consumer culture perspective in the Chinese retail market. Sustainability. 2019, 11, 1-26. doi:10.3390/su11030575

4. Alexander K.A., Freeman S., Potts T. Navigating uncertain waters: European public perceptions of integrated multi trophic aquaculture (IMTA). Environ Sci Policy. 2016, 61, 230-237. doi:10.1016/j.envsci.2016.04.020

5. Allès B., Péneau S., Kesse-Guyot E., Baudry J., Hercberg S., Méjean C. Food choice motives including sustainability during purchasing are associated with a healthy dietary pattern in French adults. Nutr. J. 2017, 16, 58. doi:10.1186/s12937-017-0279-9

6. Al-Marri W., Al-Habaibeh A., Watkins M. An investigation into domestic energy consumption behavior and public awareness of renewable energy in Qatar. Sustain Cities Soc. 2018, 41, 639-646. doi:10.1016/j.scs.2018.06.024

7. Annunziata A., Mariani A. Consumer perception of sustainability attributes in organic and local food. Recent Pat Food Nutr Agric. 2018, 2, 87-96. doi:10.2174/2212798410666171215112058

8. Ariztia T., Agloni N., Pellandini-Simányi L. Ethical living: relinking ethics and consumption through care in Chile and Brazil. Br. J. Sociol. 2018, 2, 391-411. doi:10.1111/1468-4446.12265

9. Aschemann-Witzel J., Giménez A., Ares G. Convenience or price orientation? Consumer characteristics influencing food waste behavior in the context of an emerging country and the impact on future sustainability of the global food sector. Global Environ. Chang. 2018, 49, 85-94. doi:10.1016/j.gloenvcha.2018.02.002

10. Baldi L., Bertoni D., Migliore G., Peri M. How alternative food networks work in a metropolitan area? An analysis of Solidarity Purchase Groups in Northern Italy. Agric Food Econ. 2019, 7, 20, doi:10.1186/s40100-019-0139-3

11. Ballantine P.W., Ozanne L.K., Bayfield R. Why buy free? Exploring perceptions of bottled water consumption and its environmental consequences. Sustainability. 2019, 11, 757. doi:10.3390/su11030757

12. Baudry J., Péneau S., Allès B., Touvier M., Hercberg S., Galan P., Amiot M.-J., Lairon D., Méjean C., Kesse-Guyot E. Food choice motives when purchasing in organic and conventional consumer clusters: Focus on sustainable concerns (the 19 utrient-santé cohort study). Nutrients. 2017, 9, 88. doi:10.3390/nu9020088

13. Baziana S., Tzimitra-Kalogianni E. Investigation of consumer behavior: A study on organic wine. Int. J. Soc. Ecol. Sustain. Dev. 2016, 7, 50-61. doi:10.4018/IJSESD.2016010103

14. Becker-Leifhold C.V. The role of values in collaborative fashion consumption - A critical investigation through the lenses of the theory of planned behavior. J. Clean. Prod. 2018, 199, 781-791. doi:10.1016/j.jclepro.2018.06.296

15. Bekker G.A., Fischer A.R.H., Tobi H., van Trijp H.C.M. Explicit and implicit attitude toward an emerging food technology: The case of cultured meat. Appetite. 2017, 108, 245-254. doi:10.1016/j.appet.2016.10.002

16. Biswas A., Roy M. Technology acceptance perception for promotion of sustainable consumption. Environ. Sci. Pollut. R.. 2018, 7, 6329-6339. doi:10.1007/s11356-017-0964-4

17. Blazquez M., Henninger C.E., Alexander B., Franquesa C. Consumers' Knowledge and Intentions towards Sustainability: A Spanish Fashion Perspective. Fash. Prac. 2019, 12, $34-54$. doi:10.1080/17569370.2019.1669326

18. Brochado A., Teiga N., Oliveira-Brochado F. The ecological conscious consumer behavior: are the activists different? Int. J. Consum. 2017, 41, 138-146. doi:10.1111/ijcs.12321

19. Bryła P. Regional ethnocentrism on the food market as a pattern of sustainable consumption. Sustainability. 2019, 11, 6408. doi:10.3390/su11226408 
Box A1. Cont.

20. Buda G., Pethes B., Lehota J. Dominant consumer attitudes in the sharing economy-a representative study in Hungary. Resources. 2020, 9, 1. doi:10.3390/resources9010001

21. Buldeo Rai H., Verlinde S., Macharis C. The "next day, free delivery" myth unravelled: Possibilities for sustainable last mile transport in an omnichannel environment. Int J Retail Distrib Manag. 2019, 47, 39-54. doi:10.1108/IJRDM-06-2018-0104

22. Buldeo Rai H., VerlindeS., Macharis C. Unlocking the failed delivery problem? Opportunities and challenges for smart locks from a consumer perspective. Res. Transp. Econ. 2019, doi:10.1016/j.retrec.2019.100753

23. Carley S., Yahng L. Willingness-To-pay for sustainable beer. PLoS ONE. 2018, 13, e0204917. doi:10.1371/journal.pone.0204917

24. Cavaliere A., De Marchi E., Banterle A. Exploring the adherence to the mediterranean diet and its relationship with individual lifestyle: The role of healthy behaviors, pro-environmental behaviors, income, and education. Nutrients. 2018, 10, 141. doi:10.3390/nu10020141

25. Charlebois S., McCormick M., Juhasz M. Meat consumption and higher prices: Discrete determinants affecting meat reduction or avoidance amidst retail price volatility. Brit. Food J. 2016, 118, 2251-2270. doi:10.1108/BFJ-03-2016-0121

26. Chi T., Gerard J., Dephillips A., Liu H., Sun J. Why U.S. consumers buy sustainable cotton made collegiate apparel? A study of the key determinants. Sustainability. 2019, 11,3126. doi:10.3390/su11113126

27. D'Ambrosi L. Pilot study on food sharing and social media in Italy. Brit. Food J. 2018, 120, 1046-1058. doi:10.1108/BFJ-06-2017-0341

28. Dasgupta A., Chandra B. Evolving motives for fair trade consumption: A qualitative study on handicraft consumers of India. Anthropologist. 2016, 23, 414-422. doi:10.1080/09720073.2014.11891962

29. De Bernardi P., Tirabeni L. Alternative food networks: sustainable business models for anti-consumption food cultures. Brit. Food J. 2018, 120, 1776-1791. doi:10.1108/BFJ-12-2017-0731

30. Dekhili S., Achabou M.A., Alharbi F. Could sustainability improve the promotion of luxury products? Eur. Bus. Rev. 2019, 31, 488-511. doi:10.1108/EBR-04-2018-0083

31. De-Magistris T., Gracia A. Consumers' willingness-to-pay for sustainable food products: The case of organically and locally grown almonds in Spain. J. Clean. Prod. 2016, 118, 97-104. doi:10.1016/j.jclepro.2016.01.050

32. Feil A.A., Cyrne C.C.D.S., Sindelar F.C.W., Barden J.E., Dalmoro M. Profiles of sustainable food consumption: Consumer behavior toward organic food in southern region of Brazil. J. Clean. Prod. 2020, 258. doi:10.1016/j.jclepro.2020.120690

33. Felix R., Hinsch C., Rauschnabel P.A., Schlegelmilch B.B. Religiousness and environmental concern: A multilevel and multi-country analysis of the role of life satisfaction and indulgence. J. Bus. Res. 2018, 91, 304-312. doi:10.1016/j.jbusres.2018.06.017

34. García-Herrero L., De Menna F., Vittuari M. Sustainability concerns and practices in the chocolate life cycle: Integrating consumers' perceptions and experts' knowledge. Sustain. Prod. Consum. 2019, 20, 117-127. doi:10.1016/j.spc.2019.06.003

35. Giam X., Mani L., Koh L.P., Tan H.T.W. Saving Tropical Forests by Knowing What We Consume. Conser. Lett. 2016, 9, 267-274. doi:10.1111/conl.12209

36. Goddard E., Muringai V., Boaitey A. Moral foundations and credence attributes in livestock production: Canada. J Consum Mark. 2019, 33, 418-428. doi:10.1108/JCM-02-2018-2550

37. Godin L., Sahakian M. Cutting through conflicting prescriptions: How guidelines inform "healthy and sustainable" diets in Switzerland. Appetite. 2018, 1, 123-133. doi:10.1016/j.appet.2018.08.004

38. Gollnhofer J.F. The legitimation of a sustainable practice through dialectical adaptation in the marketplace. J. Public Policy Mark. 2017, 36, 156-168. doi:10.1509/jppm.15.090

39. Hartmann L.H., Nitzko S., Spiller A. The significance of definitional dimensions of luxury food. Brit. Food J. 2016, 118, 1976-1998. doi:10.1108/BFJ-09-2015-0337

40. Hawlitschek F., Teubner T., Gimpel H. Consumer motives for peer-to-peer sharing. J. Clean. Prod. 2018, 204, 144-157. doi:10.1016/j.jclepro.2018.08.326

41. Holopainen J., Toppinen A., Lähtinen K., Rekola M. Forest certification and country of origin: Choice experiment analysis of outdoor decking material selection in E-commerce market in Finland. Forests. 2017, 8, 431. doi:10.3390/f8110431

42. Hosta M., Zabkar V. Antecedents of Environmentally and Socially Responsible Sustainable Consumer Behavior. J. Bus. Ethics. 2020. doi:10.1007/s10551-019-04416-0

43. Iyanna S., Papastathopoulos A. Measuring private sphere environmentally significant behavior of residents in Abu Dhabi. Int. J. Sustain. Soc. 2017, 9,178-192. doi:10.1504/IJSSOC.2017.086820

44. Karimzadeh S., Abbaszadeh M., Kašparová E.V.A. Incentives and inhibitors of sustainable consumption: A qualitative study among urmia informants. Pol. Sociol. 2019, 208, 477-491. doi:10.26412/psr208.06 
Box A1. Cont.

45. Khalina E.V., Solovjova J.N., Yuldasheva O.U., Pogrebova O.A. Values of sustainable development in consumer behavior: Case of Russia. Espacios. 2017, 38, 21.

46. Kim D., Kim S. The role of mobile technology in tourism: Patents, articles, news, and mobile tour app reviews. Sustainability. 2017, 9, 2082. doi:10.3390/su9112082

47. Klingler A.-L. Self-consumption with PV + Battery systems: A market diffusion model considering individual consumer behavior and preferences. Appl. Energy. 2017, 205, 1560-1570. doi:10.1016/j.apenergy.2017.08.159

48. Klöckner C.A. A stage model as an analysis framework for studying voluntary change in food choices-The case of beef consumption reduction in Norway. Appetite. 2017, 108, 434-449. doi:10.1016/j.appet.2016.11.002

49. Krause K., Battenfeld D. Coming Out of the Niche? Social Banking in Germany: An Empirical Analysis of Consumer Characteristics and Market Size. J. Bus. Ethics. 2019, 155, 889-911. doi:10.1007/s10551-017-3491-9

50. Kwok L., Huang Y. K., Hu L. Green attributes of restaurants: What really matters to consumers? Int. J. Hosp. Manag. 2016, 107-117. doi:10.1016/j.ijhm.2016.03.002

51. Kwon S. H. Green Can Be the New White for Wedding Dresses. Des. J. 2017, 20, 595-616. doi:10.1080/14606925.2017.1349410

52. Laitala K., Klepp I.G. Wool wash: Technical performance and consumer habits. Tenside Surfact Det. 2016, 53, 458-469. doi:10.3139/113.110457

53. Lakatos E.S., Cioca L.-I., Dan V., Ciomos A.O., Crisan O.A., Barsan G. Studies and investigation about the attitude towards sustainable production, consumption and waste generation in line with circular economy in Romania. Sustainability 2018, 10, 865. doi:10.3390/su10030865

54. Lakatos E.S., Dan V., Cioca L.I., Bacali L., Ciobanu A.M. How supportive are Romanian consumers of the circular economy concept: A survey. Sustainability 2016, 8, 789. doi:10.3390/su8080789

55. Lanfranchi M., Schimmenti E., Campolo M.G., Giannetto C. The willingness to pay of Sicilian consumers for a wine obtained with sustainable production method: An estimate through an ordered probit sample-selection model. Wine Econ. Policy. 2019, 8, 203-215. doi:10.1016/j.wep.2019.11.001

56. Lazaric N., Le Guel F., Belin J., Oltra V., Lavaud S., Douai A. Determinants of sustainable consumption in France: the importance of social influence and environmental values. J. Evol. Econ. 2019. doi:10.1007/s00191-019-00654-7

57. Lazowski B., Parker P., Rowlands I.H. Towards a smart and sustainable residential energy culture: Assessing participant feedback from a long-term smart grid pilot project. Energ Sustain Soc. 2018, 8, 27. doi:10.1186/s13705-018-0169-9

58. Lim E., Arita S., Joung S. Advancing sustainable consumption in Korea and Japan-from re-orientation of consumer behavior to civic actions. Sustainability 2019, 11, 6683. doi:10.3390/su11236683

59. Line N.D., Hanks L. The effects of environmental and luxury beliefs on intention to patronize green hotels: the moderating effect of destination image. J. Sustain. Tour. 2016, 24, 904-925. doi:10.1080/09669582.2015.1091467

60. Manala-O S.D., Aure P.A.H. Food waste behavior of young fast-food consumers in the Philippines. Asia-Pacific Social Science Review. 2019, 19, 72-87.

61. Mastronardi L., Romagnoli L., Mazzocchi G., Giaccio V., Marino D. Understanding consumer's motivations and behavior in alternative food networks. Brit Food J. 2019, 121, 2102-2115. doi:10.1108/BFJ-01-2019-0032

62. McLellan B.C., Chapman A.J., Aoki K. Geography, urbanization and lock-in - considerations for sustainable transitions to decentralized energy systems. J. Clean. Prod. 2016, 128,77-96. doi:10.1016/j.jclepro.2015.12.092

63. McQueen R.H., Moran L.J., Cunningham C., Hooper P.M., Wakefield K.A.-M. The impact of odour on laundering behavior: an exploratory study. Int. J. Fash. Des. Technol. Educ. 2019, 13, $20-30$. doi:10.1080/17543266.2019.1682687

64. Miranda-de la Lama G.C., Estévez-Moreno L.X., Villarroel M., Rayas-Amor A.A., María G.A., Sepúlveda W.S. Consumer Attitudes Toward Animal Welfare-Friendly Products and Willingness to Pay: Exploration of Mexican Market Segments. J Appl Anim Welf Sci. 2019, 22, 13-25. doi:10.1080/10888705.2018.1456925

65. Moon D., Amasawa E., Hirao M. Laundry habits in Bangkok: Use patterns of products and services. Sustainability 2019, 11, 4486. doi:10.3390/su11164486

66. My N.H.D., Rutsaert P., Van Loo E.J., Verbeke W. Consumers' familiarity with and attitudes towards food quality certifications for rice and vegetables in Vietnam. Food Control. 2017, 82, 74-82. doi:10.1016/j.foodcont.2017.06.011

67. Nassivera F., Troiano S., Marangon F., Sillani S., Markova Nencheva I. Willingness to pay for organic cotton: Consumer responsiveness to a corporate social responsibility initiative. Brit Food J. 2017, 119, 1815-1825. doi:10.1108/BFJ-12-2016-0583 
Box A1. Cont.

68. Pambo K.O., Mbeche R.M., Okello J.J., Mose G.N., Kinyuru J.N. Intentions to consume foods from edible insects and the prospects for transforming the ubiquitous biomass into food. Agr Hum Values. 2018, 35, 885-898. doi:10.1007/s10460-018-9881-5

69. Panzone L., Hilton D., Sale L., Cohen D. Socio-demographics, implicit attitudes, explicit attitudes, and sustainable consumption in supermarket shopping. J. Econ. Psychol. 2016, 55, 77-95. doi:10.1016/j.joep.2016.02.004

70. Papaoikonomou E., Cascon-Pereira R., Ryan G. Constructing and communicating an ethical consumer identity: A Social Identity Approach. J. Consum. Cult. 2016, 16, 209-231. doi:10.1177/1469540514521080

71. Park H., Lee M.-Y., Koo W. The four faces of apparel consumers: Identifying sustainable consumers for apparel. J. Fash. Mark. Manag. 2017, 8, 298-312. doi:10.1080/20932685.2017.1362988

72. Péneau S., Fassier P., Allès B., Kesse-Guyot E., Hercberg S., Méjean C. Dilemma between health and environmental motives when purchasing animal food products: Sociodemographic and nutritional characteristics of consumers. BMC Public Health. 2017, 17, 876. doi:10.1186/s12889-017-4875-6

73. Pieniak Z., Zakowska-Biemans S., Kostyra E., Raats M. Sustainable healthy eating behavior of young adults: Towards a novel methodological approach. BMC Public Health. 2016, 16, 577. doi:10.1186/s12889-016-3260-1

74. Piligrimiene Z., Žukauskaite A., Korzilius H., Banyte J., Dovaliene A. Internal and external determinants of consumer engagement in sustainable consumption. Sustainability. 2020, 12, 1349. doi:10.3390/su12041349

75. Polenzani B., Riganelli C., Marchini A. Sustainability perception of local extra virgin olive oil and consumers' attitude: A new Italian perspective. Sustainability. 2020, 12, 920. doi:10.3390/su12030920

76. Rajadurai J., Bathmanathan V., Azami N. Gen Y green purchasing behavior in relation YO energy conservation and environmental preservation products in Malaysia. Int. J. Eng. Technol. Innov. 2018, 7, 810-818. doi:10.14419/ijet.v7i4.35.23113

77. Reardon K., Padfield R., Salim H.K. Consumers don't see tigers dying in palm oil plantations": a cross-cultural comparative study of UK, Malaysian and Singaporean consumer views of palm oil. Asian Geogr. 2019, 36, 117-141. doi:10.1080/10225706.2019.1621187

78. Ricci E.C., Banterle A. The effects of expo Milano 2015 on consumer food choices. Economia Agro-Alimentare. 2018, 2, 233-244. doi:10.3280/ECAG2018-002008

79. Rioux L., Scrima F., Bouzid D., Moffat É., Mokounkolo R. The effects of academic socialisation on students' consumer behavior. Soc. Psychol. Educ. 2017, 20, 693-705. doi:10.1007/s11218-017-9385-y

80. Roos D., Hahn R. Understanding Collaborative Consumption: An Extension of the Theory of Planned Behavior with Value-Based Personal Norms. J. Bus. Ethics. 2019, 158, 679-697. doi:10.1007/s10551-017-3675-3

81. Rubright H., Kline C., Viren P.P., Naar A., Oliver J. Attraction sustainability in North Carolina and its impact on decision-making. Tour. Manag. Perspect. 2016, 19, 1-10. doi:10.1016/j.tmp.2016.04.002

82. Sacchi G. The Ethics and Politics of Food Purchasing Choices in Italian Consumers' Collective Action. J. Agric. Environ. Ethics. 2018, 31, 73-91. doi:10.1007/s10806-018-9710-2

83. Santeramo F.G., Carlucci D., De Devitiis B., Nardone G., Viscecchia R. On consumption patterns in oyster markets: The role of attitudes. Mar Policy. 2017, 79, 54-61. doi:10.1016/j.marpol.2017.02.005

84. Santisi G., Morando M., Sciacca A. Craft beer and intensity of purchase: A psychological analysis of consumer intentions. Quality - Access to Success. 2018, 19, 451-457.

85. Satapathy S., Sangle S., Unnikrishnan S. Determinants of technology-based product adoption by consumers. World Rev. Sci. Technol. Sustain. Dev. 2018, 14, 85-99. doi:10.1504/WRSTSD.2018.092828

86. Schmidt K. Predicting the consumption of expired food by an extended Theory of Planned Behavior. Food Qual Prefer. 2019, 78. doi:10.1016/j.foodqual.2019.103746

87. Shahsavar T., Kubeš V., Baran D. Willingness to pay for eco-friendly furniture based on demographic factors. J. Clean. Prod. 2020, 250. doi:10.1016/j.jclepro.2019.119466

88. Shamsi M.S., Siddiqui Z.S. Green product and consumer behavior: An analytical study. Pertanika J. Soc. Sci. Hum. 2017, 25, 1545-1554.

89. Shao J., Ünal E. What do consumers value more in green purchasing? Assessing the sustainability practices from demand side of business. J. Clean. Prod. 2019, 209, 1473-1483. doi:10.1016/j.jclepro.2018.11.022

90. Si H., Shi J.-G., Tang D., Wu G., Lan J. Understanding intention and behavior toward sustainable usage of bike sharing by extending the theory of planned behavior. Resour Conserv Recycl. 2020, 152. doi:10.1016/j.resconrec.2019.104513

91. Siegrist M., Hartmann C. Impact of sustainability perception on consumption of organic meat and meat substitutes. Appetite. 2019, 132, 196-202. doi:10.1016/j.appet.2018.09.016 
Box A1. Cont.

92. Simha P., Lalander C., Ramanathan A., Vijayalakshmi C., McConville J.R., Vinnerås B., Ganesapillai M. What do consumers think about recycling human urine as fertiliser? Perceptions and attitudes of a university community in South India. Water Res. 2018, 143, 527-538. doi:10.1016/j.watres.2018.07.006

93. Song L., Lim Y., Chang P., Guo Y., Zhang M., Wang X., Yu X., Lehto M.R., Cai H. Ecolabel's role in informing sustainable consumption: A naturalistic decision making study using eye tracking glasses. J. Clean. Prod.. 2019, 218, 685-695. doi:10.1016/j.jclepro.2019.01.283

94. Stranieri S., Ricci E.C., Banterle A. Convenience food with environmentally-sustainable attributes: A consumer perspective. Appetite. 2017, 116, 11-20. doi:10.1016/j.appet.2017.04.015

95. Vega-Zamora M., Torres-Ruiz F.J., Parras-Rosa M. Key determinants of organic food consumption: The case of olive oil in Spain. HortScience. 2018, 53, 1172-1178. doi:10.21273/HORTSCI13080-18

96. Wei X., Jung S. Understanding Chinese consumers' intention to purchase sustainable fashion products: The moderating role of face-saving orientation. Sustainability. 2017, 9, 1570. doi:10.3390/su9091570

97. Wong E.Y.C., Chan F.F.Y., So S. Consumer perceptions on product carbon footprints and carbon labels of beverage merchandise in Hong Kong. J. Clean. Prod. 2020, 242. doi:10.1016/j.jclepro.2019.118404

98. Wu C.-S., Zhou X.-X., Song M. Sustainable consumer behavior in China: an empirical analysis from the Midwest regions. J. Clean. Prod. 2016, 134, 147-165. doi:10.1016/j.jclepro.2015.06.057

99. Yates L., Evans D. Dirtying Linen: Re-evaluating the sustainability of domestic laundry. Environ. Policy Gov. 2016, 26, 101-115. doi:10.1002/eet.1704

100. Zorell C.V., Yang M. Real-world sustainable citizenship between political consumerism and material practices. Soc. Sci. 2019, 8, 311. doi:10.3390/socsci8110311.

\section{References}

1. Peattie, K.; Collins, A. Guest editorial: Perspectives on sustainable consumption. Int. J. Consum. 2009, 33, 107-112. [CrossRef]

2. Lim, W.M. Inside the sustainable consumption theoretical toolbox: Critical concepts for sustainability, consumption, and marketing. J. Bus. Res. 2017, 78, 69-80. [CrossRef]

3. Western Cape Education Department. Our Common Future: World Commission on Environment and Development; Oxford University Press: Oxford, UK, 1987.

4. United Nations. Transforming our World: The 2030 Agenda for Sustainable Development. 2015. Available online: https://sustainabledevelopment.un.org/ (accessed on 10 May 2020).

5. Lim, W.M. A blueprint for sustainability marketing: Defining its conceptual boundaries for progress. Mark. Theory 2016, 16, 232-249. [CrossRef]

6. Elkington, J. Enter the Triple Bottom Line. 2004. Available online: http://www.johnelkington.com (accessed on 15 April 2020).

7. Chabowsky, B.R.; Mena, J.A.; Gonzalez-Pardon, T. The Structure of Sustainability Research in Marketing, 1958-2008: A Basis for Future Research Opportunities. J. Acad. Mark. 2010, 39, 55-70. [CrossRef]

8. Hanss, D.; Böhm, G. Sustainability seen from the perspective of consumers. Int. J. Consum. Stud. 2012, 36, 678-687. [CrossRef]

9. Stern, C.P. Toward a Coherent Theory of Environmentally Significant Behavior. J. Soc. Issues 2000, 56, 407-424. [CrossRef]

10. Trudel, R. Sustainable consumer behavior. Consum. Psychol. Rev. 2019, 2, 85-96. [CrossRef]

11. Agarwal, N.; Steinmetz, R. Sharing Economy: A Systematic Literature Review. Int. J. Innov. Technol. Manag. 2019, 16. [CrossRef]

12. Ter Huurne, M.; Ronteltap, A.; Corten, R.; Buskens, V. Antecedents of trust in the sharing economy: A systematic review. J. Consum. Behav. 2017, 16, 485-498. [CrossRef]

13. Hall, C.M.; Dayal, N.; Majstorovic, D.; Mills, H.; Paul-Andrews, L.; Wallace, C.; Truong, V.D. Accommodation Consumers and Providers' Attitudes, Behaviours and Practices for Sustainability: A Systematic Review. Sustainability 2016, 8, 625. [CrossRef]

14. Parajuly, K.; Fitzpatrick, C.; Muldoon, O.; Kuehr, R. Behavioral change for the circular economy: A review with focus on electronic waste management in the EU. Resour. Conserv. Recy. 2020, 6, 100035. [CrossRef] 
15. Bunga Bangsa, A.; Schlegelmilch, B.B. Linking sustainable product attributes and consumer decision-making: Insights from a systematic review. J. Clean. Prod. 2020, 245, 118902. [CrossRef]

16. Sanchez-Sabate, R.; Sabaté, J. Consumer Attitudes Towards Environmental Concerns of Meat Consumption: A Systematic Review. Int. J. Environ. Res. Pub. Health 2019, 16, 1220. [CrossRef] [PubMed]

17. Tobi, R.C.A.; Harris, F.; Rana, R.; Brown, K.A.; Quaife, M.; Green, R. Sustainable Diet Dimensions. Comparing Consumer Preference for Nutrition, Environmental and Social Responsibility Food Labelling: A Systematic Review. Sustainability 2019, 11, 6575. [CrossRef]

18. Maesano, G.; Carra, G.; Peri, I. How Do Consumers Perceive Sustainable Wine? A Review. Qual. Access Success 2019, 20, 351-357.

19. Amarando, M.; Assenov, I.; Visuthismajarn, P. A Systematic Review of Sustainable Wine Tourism Research in Asia 2000-2018. Afr. J. Hosp. Tour. Leis. 2019, 8, 1-24.

20. Kumar, P.; Polonsky, M.J. An analysis of the green consumer domain within sustainability research: 1975 to 2014. Australas. Mark. J. 2017, 25, 85-96. [CrossRef]

21. Shao, J. Sustainable consumption in China: New trends and research interests. Bus. Strategy Environ. 2019, 28, 1507-1517. [CrossRef]

22. Moher, D.; Liberati, A.; Tetzlaff, J.; Altman, D.G. Preferred reporting items for systematic reviews and meta-analyses: The PRISMA statement. Ann. Intern. Med. 2009, 151, 264-269. [CrossRef]

23. Lancia, F. T-LAB 9.1-User's Manual. 2015. Available online: https://www.tlab.it/download/ (accessed on 18 April 2020).

24. Lancia, F. The Logic of the T-Lab Tools Explained. 2012. Available online: http://www.tlab.it/en/toolsexplained. php (accessed on 18 April 2020).

25. Echegaray, F.; Hansstein, F.V. Assessing the intention-behavior gap in electronic waste recycling: The case of Brazil. J. Clean. Prod. 2017, 142, 180-190. [CrossRef]

26. Wilhelms, M.-P.; Henkel, S.; Falk, T. To earn is not enough: A means-end analysis to uncover peer-providers' participation motives in peer-to-peer carsharing. Technol. Forecast. Soc. Chang. 2017, 125, 38-47. [CrossRef]

27. Hoek, A.C.; Pearson, D.; James, S.W.; Lawrence, M.A.; Friel, S. Shrinking the food-print: A qualitative study into consumer perceptions, experiences and attitudes towards healthy and environmentally friendly food behaviours. Appetite 2017, 108, 117-131. [CrossRef] [PubMed]

28. Thøgersen, J. Sustainable food consumption in the nexus between national context and private lifestyle: A multi-level study. Food Qual. Prefer. 2017, 55, 16-25. [CrossRef]

29. Tukker, A.; Huppes, G.; Guinée, J.; Heijungs, R.; De Koning, A.; Van Oers, L.; Suh, S.; Geerken, T.; Van Holderbeke, M.; Jansen, B.; et al. Environmental Impact of Products (EIPRO): Analysis of the Life Cycle Environmental Impacts Related to the Final Consumption of the Eu-25; European Commission Joint Research Centre: Brussels, Belgium, 2005.

30. Prothero, A.; Dobscha, S.; Freund, J.; Kilbourne, W.E.; Luchs, M.G.; Ozanne, L.K.; Thøgersen, J.; Freund, J. Sustainable Consumption: Opportunities for Consumer Research and Public Policy. J. Public Policy Mark. 2011, 30, 31-38. [CrossRef]

31. Toffel, M.W. The growing strategic importance of end-of-life product management. Calif. Manag. Rev. 2004, 45, 102-129. [CrossRef]

32. Wallin, J.A. Bibliometric Methods: Pitfalls and Possibilities. Basic Clin. Pharmacol. 2005, 97, $262-275$. [CrossRef]

(C) 2020 by the authors. Licensee MDPI, Basel, Switzerland. This article is an open access article distributed under the terms and conditions of the Creative Commons Attribution (CC BY) license (http://creativecommons.org/licenses/by/4.0/). 